\title{
What Explains Differences in International Performance? TIMSS Researchers Continue to Look for Answers
}

Deborah Nelson

Follow this and additional works at: https://repository.upenn.edu/cpre_policybriefs

Part of the Curriculum and Instruction Commons, Education Policy Commons, International and Comparative Education Commons, and the Science and Mathematics Education Commons

\section{Recommended Citation}

Nelson, Deborah. (2003). What Explains Differences in International Performance? TIMSS Researchers Continue to Look for Answers. CPRE Policy Briefs.

Retrieved from https://repository.upenn.edu/cpre_policybriefs/26

View on the CPRE website.

This paper is posted at ScholarlyCommons. https://repository.upenn.edu/cpre_policybriefs/26

For more information, please contact repository@pobox.upenn.edu. 


\title{
What Explains Differences in International Performance? TIMSS Researchers Continue to Look for Answers
}

\author{
Abstract \\ The Third International Mathematics and Science Study (TIMSS)-1995 and its successor, TIMSS-1999, \\ provide researchers, policymakers, and educators with an unprecedented opportunity to explore the \\ possible relationships between educational policies and student achievement in an international context. \\ Due to the amount and complexity of the TIMSS data, analyses have proceeded in phases, each providing \\ a more detailed and sophisticated understanding of these relationships. This Brief is the third in the \\ Consortium for Policy Research in Education's (CPRE) series reporting on the policy implications of \\ TIMSS data. It summarizes results of recently completed TIMSS research that explores in greater detail \\ questions raised in initial analyses. \\ Earlier analyses of TIMSS data were based largely on observed differences between instructional \\ variables in the United States and in high-achieving TIMSS nations. This was a kind of "benchmarking" \\ approach in which certain practices were hypothesized to increase student achievement. Some of the \\ research summarized in this Brief continues this earlier work by exploring additional differences between \\ policy and practice in the United States and in other TIMSS nations. Other studies expand on this work by \\ looking for instructional variables that might explain differences in student achievement across a broader \\ range of TIMSS nations. Results do not yield simple lessons and may thus be frustrating for those who \\ hoped that TIMSS might prescribe specific recommendations for policy and practice. Recent research \\ does, however, continue to raise important questions about the relationships between policy, practice, and \\ student achievement in an international context. The summary presented here highlights key issues that \\ emerge from this work. \\ Disciplines \\ Curriculum and Instruction | Education Policy | International and Comparative Education | Science and \\ Mathematics Education

\section{Comments} \\ View on the CPRE website.
}




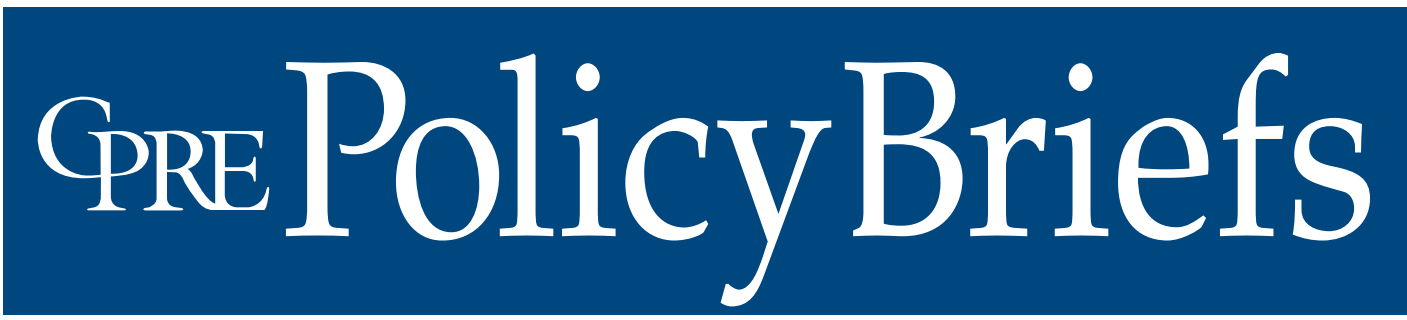

Reporting on Issues and Research in Education Policy and Finance

\section{What Explains Differences in Internation- al Performance? TIMSS Researchers Continue to Look for Answers}

\section{by Deborah I. Nelson}

The Third International Mathematics and Science Study (TIMSS)-1995 and its successor, TIMSS-1999, provide researchers, policymakers, and educators with an unprecedented opportunity to explore the possible relationships between educational policies and student achievement in an international context. Due to the amount and complexity of the TIMSS data, analyses have proceeded in phases, each providing a more detailed and sophisticated understanding of these relationships. This Brief is the third in the Consortium for Policy Research in Education's (CPRE) series reporting on the policy implications of TIMSS data. It summarizes results of recently completed TIMSS research that explores in greater detail questions raised in initial analyses. ${ }^{1}$

Earlier analyses of TIMSS data were based largely on observed differences between instructional variables in the United States and in high-achieving TIMSS nations. This was a kind of "benchmarking" approach in which certain practices were hypothesized to increase student achievement. Some of the research summarized in this Brief continues this earlier work by exploring additional differences between policy and practice in the United States and in other TIMSS nations. Other studies expand on this work by looking for instructional variables that might explain differences in student achievement across a broader range of TIMSS nations. Results do not yield simple lessons and may thus be frustrating for those who hoped that TIMSS might prescribe specific recommendations for policy and practice. Recent research does, however, continue to raise important questions about the relationships between policy, practice, and student achievement in an international context. The summary presented here highlights key issues that emerge from this work.

\section{Curriculum Content and Implementation}

In Why Schools Matter, Schmidt et al. (2001) demonstrate significant relationships within all TIMSS nations between the content of curriculum, its implementation, and student achievement. Central to this relationship is the time devoted to instruction on specific subtopics, especially when the instruction reflects demanding expectations for students. This work expands upon earlier research that suggested a relationship between the content of curriculum and student achievement within higher performing TIMSS nations. It does so by looking across a greater number of TIMSS nations and by using more sophisticated measures of curriculum and student learning. ${ }^{2}$ According to Schmidt et al. (2001), results confirm the powerful effects that schools have on student learning and justify continuing efforts to improve instruction.

The study does not identify any single instructional variable that accounts for differences in student achievement across nations. While content standards and textbooks are related both to instruction and student achievement, their effects vary in complex ways among nations. In the United States, for example, textbooks are more closely correlated to student learning than are standards. Textbooks influence teachers' choice of subtopics for instruction and the amount of time they spend teaching these topics. In other countries, standards play a greater role,
September 2003

RB-37

Graduate School of Education

University of

Pennsylvania

\section{Consortium for Policy Research in Education}

University of Pennsylvania

Harvard University

Stanford University

University of Michigan

University of Wisconsin-Madison 
though their effects are also mediated through textbooks. ${ }^{3}$

These results demonstrate the difficulty of taking simple policy lessons from TIMSS data. In the work reported below, however, Schmidt and his colleagues at the U.S. TIMSS National Research Center at Michigan State University explored implications from TIMSS for improvement of standards, textbooks, and course offerings in the United States.

\section{Standards}

Schmidt, Houang, and Cogan (2002) use TIMSS data to suggest ways to improve the coherence of U.S. mathematics standards. According to Schmidt et al. (2002), standards are coherent if they are "articulated over time as a sequence of topics and performances that are logical and reflect, where appropriate, the sequential or hierarchical nature of the disciplinary content from which the subject matter derives." The study compares composite mathematics ${ }^{4}$ standards of the 20 highest achieving TIMSS nations with those of 21 states and 50 districts in the United States. Results indicate that standards in the United States are less coherent than the international benchmark standards. Schmidt et al. (2002) observe that standards in the United States seem more like an arbitrarily arranged laundry list of skills than a logical sequence of skills that build on each other. They attribute this partially to the fact that standards in the United States contain more topics repeated across more grades than do standards in higher achieving nations. They suggest that pressures resulting from political compromise and shared decision making make inclusion a more influential organizing principle than coherence.

In contrast, standards in the highest achieving nations seem to follow a logical sequence - what Schmidt et al. (2002) refer to as a "three-tier pattern of increasing mathematical complexity." Standards covering grades 1 through 4 place emphasis primarily on arithmetic, including common and decimal fractions, rounding, and estimation. The second tier, which includes grades 5 and 6 , appears to serve a transitional function, moving away from arithmetic topics and introducing more advanced topics such as negative numbers, integers, and their properties;
CPRE is funded by the Institute of Education Sciences, United States Department of Education. This Brief was funded under OERI Grant No. R215U980021308. Opinions expressed in this Brief are those of the author and do not necessarily reflect the views of the Institute of Education Sciences, the United States Department of Education, CPRE, or its institutional members.

percentages; two-dimensional coordinate geometry; and geometric transformations. Standards covering grades 7 and 8 form the third tier that emphasizes number theory, algebra, and geometry.

\section{Textbooks}

As reported above, textbooks have a greater effect on instruction in the United States than they do in other nations. Valverde, Bianchi, Wolfe, Schmidt, and Houang (2002) argue that textbooks are essential tools for translating standards into opportunities to learn in the classroom. In the absence of common standards, they may also represent a de facto national curriculum in the United States. Previous work indicated that content coverage in U.S. textbooks is "a mile wide and an inch deep" (Schmidt, McKnight, \& Raizen, 1997). Valverde et al. extend this work to look at differences in the structure of textbooks and in the types of pedagogical activities they model. Results suggest that, like standards, textbooks in the United States are less focused and coherent than those in higher achieving nations. Content in U.S. textbooks is often presented in an episodic, disjointed manner. Valverde et al. cite Japan, Singapore, and Hong Kong as examples of countries whose textbooks reflect a greater appreciation for the structure of mathematics and science as disciplines. They also note fewer differences across TIMSS nations in the types of classroom activities modeled in textbooks. Textbooks in most nations model a pedagogy based on mastery of specific material or skills. In this sense, Valverde et al. argue, few textbooks have changed to reflect the emphasis of standards on problem solving, reasoning, and communication. ${ }^{5}$

\section{Course Offerings}

Cogan, Schmidt, and Wiley (2001) expand upon earlier reports of the "splintered" nature of the eighth-grade mathematics curriculum by using TIMSS data to look at curricular variation between educational settings in the United States. ${ }^{6}$ The study finds a 
"bewildering" array of different curricular offerings between schools, between courses, and even between classrooms offering similar courses in the same school. Exacerbating this variation is the fact that course titles often do not accurately reflect content being covered in class. For example, $30 \%$ of students are using textbooks that do not match the title of courses in which they are enrolled? This finding suggests that the mathematics curriculum may vary even more than it appears and raises questions about functional equivalency between courses.

Cogan et al. believe that curricular variation results in significant disparities between schools and classrooms in students' opportunities to learn. For example, $30 \%$ of students attend schools that do not offer an algebra I class. This figure is greater for students attending rural or urban schools ( $40 \%$ ) than it is for their suburban counterparts (20\%). This variation is especially problematic in the context of standards-based reforms that demand higher levels of achievement from all students. Curricular variation, or "tracking," is commonly justified in the United States as a means of matching students' abilities and interests with appropriate courses. Cogan et al. contend, however, that this argument is undermined by the seemingly random pattern of curricular offerings across schools.

The study also offers additional evidence of the need to improve the rigor of mathematics curricula in the United States; $57 \%$ of eighth-grade students are enrolled in "regular" math classes that rank low on a TIMSSderived scale of topic difficulty. Cogan et al. note that efforts to improve coherence and rigor at the eighth-grade level must encompass all prior grades as differences in opportunity to learn at the eighth-grade level likely reflect differences in all prior years of schooling.

\section{Classroom Instruction}

The TIMSS-1999 Video Study suggests ways to think about the improvement of classroom instruction in an international context. Data for the study are taken primarily from videotaped lessons sampled from eighth-grade classrooms in the United States and six higher achieving TIMSS nations: Australia, the Czech Republic, Hong Kong,
Japan, the Netherlands, and Switzerland. Researchers Ron Gallimore and James Stigler, both of the University of California at Los Angeles, and James Hiebert of the University of Delaware, focus on characterizing the content, form, and pedagogical style of mathematics and science lessons. The study expands upon the TIMSS-1995 videotape study by looking at more nations and by exploring themes and questions in greater depth. Results reported here are from the first phase of analysis focused on mathematics lessons (Hiebert et al., 2003). ${ }^{8}$

Results indicate that the lesson characteristics studied do not, in themselves, account for differences in student achievement as measured by TIMSS. However, the study reports a number of similarities and differences among lessons in the seven nations. ${ }^{9}$ These can be used as analytic tools by those seeking to reflect on and improve instruction in an international context. It is important to note, however, that none of the lesson characteristics reported here are linked directly with student achievement in this study.

The study reports a number of differences between classroom instruction in the United States and in most of the higher achieving nations. For example, teachers in the United States spend more than twice the amount of time reviewing content than do teachers in the highest achieving nations sampled Japan and Hong Kong. ${ }^{10}$ Teachers in the United States are also more than five times as likely to spend entire lessons reviewing content than teachers in Japan and Hong Kong who devote more lesson time to introduction and practice of new content. The study also reports one especially marked difference between pedagogical practice in the United States and the highest achieving nations: lessons in the United States are much less likely to focus on making connections among mathematical facts, procedures, and concepts. Less than $1 \%$ of mathematical problems used in U.S. lessons are discussed in a way that emphasizes these connections. Discussion of problems that emphasize connections is a more regular feature of lessons in the highest achieving nations, especially Japan. ${ }^{11}$ 
The study reports several additional ways in which Japanese mathematics lessons are different from those in the six other nations. ${ }^{12}$ These differences concern the nature of mathematical problems used in Japanese classrooms and the way these problems are organized within lessons. Japanese lessons contain a greater number of problems that researchers consider to be high in procedural complexity - defined as the number of steps it takes to solve a problem. The vast majority of problems used in lessons by the other six nations are considered to be low in procedural complexity. In Japan, $84 \%$ of problems used in lessons are of high or moderate complexity. As mentioned above, more lesson problems in Japan are devoted to making mathematical connections than are problems in other nations $(54 \%$ of problem statements - more than three times as much as most other nations). In all the other nations, more problems are designed to use procedures than they are to make connections or state concepts. In Japan, problems are often presented based on their mathematical relationships to each other ( $42 \%$ of problems). The majority of problems in other nations are presented as repetitions of previous problems (at least 65\%), compared to only $40 \%$ in Japan.

In addition to these differences, researchers also note a number of similarities in lessons across nations. These include a focus on solving mathematical problems, use of textbooks or worksheets to guide lessons, a tendency for teachers to speak much more than students (a ratio of 8:1 words), a combination of whole-group and private activity (mostly individual rather than pairs or groups), and a general focus on three topics within the eighth-grade curriculum: numbers, geometry, and algebra (combined, these topics represent $82 \%$ of problems per lesson, on average). ${ }^{13}$

\section{Educating Disadvantaged Students}

Baker, Goesling, and LeTendre (2002) report that while the overall quality of schooling in wealthy and less-wealthy nations alike has improved over the last 30 years, family socio-economic status is playing an even greater role in influencing educational outcomes than it has in the past. Baker et al. suggest that effective education of dis- advantaged students is critical if the United States hopes to educate all children to be competitive in an international context.

Some TIMSS data suggest that the United States may not be doing as well as many other nations in the education of socio-economically disadvantaged children. Baker et al. find that disadvantaged students in the United States achieve at significantly lower levels than similarly disadvantaged students in other developed, wealthy nations sampled in TIMSS. Baker et al. suggest that improving the education of disadvantaged students would do much to improve the overall standing of the United States in TIMSS mathematics achievement. For example, if the United States educated disadvantaged children as well as Sweden does, it would score above five wealthy nations it currently performs below.

Several studies suggest factors that contribute to the less effective education of disadvantaged students in the United States. Baker et al. report that schools serving disadvantaged students in the United States tend to exist in systems of greater inequality and have lower absolute levels of instructional resources than do schools serving disadvantaged students in other nations. As reported above, Cogan et al. note that students in rural and urban schools have less access to higherlevel mathematics courses than do their suburban counterparts. Further, students in urban schools with high numbers of minority students are more likely to be in classes focused on arithmetic than students in lowminority suburban schools. These differences in opportunities to learn may have consequences that go beyond achievement. Akiba, LeTendre, Baker, and Goesling (2002) use TIMSS data to suggest that nations producing greater achievement differences between high- and low-achieving students also report more school violence.

\section{No Simple Solutions}

Much of the TIMSS research conducted over the last five years attempted to find cross-national relationships between specific instructional variables and student achievement. Few clear relationships emerged from this work. Among the hundreds of policyand practice-related variables examined at 
Pennsylvania State University and the Center for Research and Evaluation in Social Policy (CRESP) at the University of Pennsylvania, several did indicate positive relationships with student achievement. These relationships are difficult to translate into direct implications for policy and practice. ${ }^{14}$ There are, however, positive lessons to be learned from the absence of simple, cross-national relationships, both about understanding the complex nature of educational systems and about the challenges of conducting analyses of international comparative data.

According to Baker (2002), whose research team at Penn State has conducted a series of TIMSS analyses, the absence of simple cross-national relationships should send a clear message about avoiding the kinds of policy prescriptions that are often associated with international comparative data. Their research, for example, challenges a number of commonly held assumptions about the negative characteristics of American high schools in comparison to their international counterparts on such factors as school violence, learning climate, and students' lack of motivation or attention to school work (Baker, 2002). Baker cautions against policies based on simplistic interpretations of international data, suggesting instead that "it may take a whole case of silver bullets to make real changes in the international competitiveness of American secondary education." Rather than looking for easy answers, policymakers must seek to understand the important relationships among curriculum, accountability, distribution of resources, and other sources of influence on student achievement.

Schmidt et al. (2001) believe that while TIMSS data provide an important framework for reform, they cannot yield specific, generalizable policy solutions. They caution, "We cannot copy a single aspect of curriculum or any other part of education from another country. Those are part of national systems and there is not enough data in TIMSS to be able to account for all the different factors." Using TIMSS as a framework, they believe that policymakers must instead craft solutions from analysis of additional data related to student achievement, curriculum, and implementation in local contexts. ${ }^{15}$

\section{Using TIMSS to Craft Local Solutions}

The St. Clair County Promoting Results in Science and Math (PRISM) initiative provides an example of how TIMSS instruments can be used to collect the kind of data useful in crafting specific reforms at the local level (Schmidt et al., 2002). The initiative brings together researchers from the U.S. TIMSS National Research Center at Michigan State University and seven districts that are committed to using TIMSS-derived data to look at relationships between curriculum and learning. These districts administered TIMSS assessments across a greater number of grades than are tested in TIMSS. ${ }^{16}$ In addition, students, teachers, administrators, and curriculum directors completed questionnaires yielding extensive data about curriculum coverage of specific subtopics. These data permit districts to make broad comparisons between their districts, the United States, and 40 other countries on measures of student achievement and curriculum. Unlike TIMSS, they also yield information about student achievement and curriculum coverage at the classroom, school, and district levels. Especially helpful for these districts were analyses suggesting relationships between student achievement and curriculum coverage of specific subtopics.

Results indicated similarities between the St. Clair districts and the United States in general on both student achievement and curriculum content. These results reinforced existing research suggesting the need for states and districts to improve the rigor and coherence of standards and curriculum. The specificity of the data allowed district administrators and teachers to observe more direct relationships between coverage of content and learning than is possible with the nationallevel TIMSS data. PRISM data have provided the base for district-sponsored professional development in which teachers and administrators conduct close analyses of content coverage and student achievement at all levels. ${ }^{17}$ As a result of this process, the districts are working together to develop common standards that address problems uncovered in their data. 


\section{Methodological Issues Associated with Analyzing International Comparative Data}

Researchers' experiences with TIMSS have yielded a number of lessons about the challenges involved in designing international comparative studies and analyzing their data.

\section{Differentiating Cumulative Achievement and Growth}

A number of researchers have highlighted problems associated with looking for relationships between cumulative achievement measures, such as the TIMSS eighth-grade achievement score, and other variables, such as curriculum or instruction, that are grade specific. The cumulative achievement measures reflect students' learning over many years of schooling, not just in the grade assessed. More precise measures are necessary to link student achievement with instructional variables. Growth scores that reflect students' learning in a specific grade are more likely to interact with curriculum and instruction variables for that grade. (As described earlier, Schmidt et al. [2001] use measures that capture achievement growth over eighth grade in specific subtopics. Curriculum indicators are also specified by subtopic.) Schmidt et al. (2001) point out that the cumulative measures are helpful as a "yardstick" to compare achievement among nations. But growth measures are more valuable for those who hope to use international comparative research as a kind of "laboratory" of different approaches to policy and practice.

\section{Understanding Contextual Relationships}

Relationships between educational variables and student achievement at one level of analysis - for example, the national - often do not hold up at other levels, such as the school or student. Results must always be interpreted with caution when they are taken out of context. A number of researchers have found, for example, that variables predicting student achievement within particular countries do not hold up in cross-national analyses. The virtual absence of cross-national educational variables predicting student achievement suggests that educational policies and instructional practices are difficult to separate from the contexts in which they are developed and implemented. Schmidt et al. (2001) note that, even with the extensive data it provides, TIMSS cannot explain the way something complex, like curriculum, works across countries. TIMSS can be used to get a broad sense of the kinds of relationships that exist, but qualitative studies are necessary to understand the nature of those relationships within particular countries.

Understanding Others, Educating Ourselves, a National Research Council report released by the Board on International Comparative Studies in Education at the National Academy of Sciences, notes that false expectations are raised by those who suggest that isolated practices can be easily transferred between different educational systems. It recommends that the United States take a more systematic approach to exploring international differences in policy and practice by balancing large-scale comparative assessments with more interpretive studies. This approach would require long-term funding commitments to support continuing research as well as the infrastructure and leadership necessary to coordinate a research agenda.

\section{Interpreting Achievement Scores}

Context may also affect the relationship between what students know and what they demonstrate on achievement tests. For example, Boe, May, Shin, and Boruch (2002) demonstrate that more than half of the variability in national mean achievement scores can be accounted for by "student task persistence." This measure, derived from the TIMSS student questionnaire, shows that students vary greatly among countries in the degree to which they apply themselves in test taking. 


\section{Conclusion}

Recent analyses of TIMSS data continue to raise important issues for improvement of mathematics and science instruction. They also provide guidance about how future efforts at international data collection and analysis might clarify differences in policy and practice and their links with student achievement. Finally, the TIMSS experience highlights an important lesson for all those who hope to use international comparative data for improvement at the national and local levels. These data can provide critical tools for shaping reform agendas, but they must always be interpreted with caution and with rigorous and thoughtful attention to contextual factors that affect educational policies and outcomes.

\section{About the Author}

Deborah Nelson was formerly a research assistant at the Consortium for Policy Research in Education where she worked on issues related to districts' use of data and policymakers' use of educational research. She is currently conducting research on district policies related to professional development and instructional improvement.

\section{End Notes}

1. See Dunson (2000) and Nelson (2002) for details about the nature of TIMSS data and prior analyses.

2. Specifically, the study explores relationships between intended curriculum (as measured by content standards and proportion of textbook space focused on specific topics), implemented curriculum (teacher time and focus on topics), and estimated national gains in tested areas at the eighth-grade level. This study uses more precise measures of curriculum and achievement than have been used with TIMSS analyses in the past. It distinguishes between "intended" curriculum (as measured by curriculum standards and textbook coverage of specific subtopics) and "implemented" curriculum (as measured by the topics teachers emphasize and how much time they spend on them). As an achievement measure, the study looks at eighth-grade gains, computed from differences in seventhand eighth-grade scores, rather than looking at just eighth-grade scores. Schmidt et al. (2001) believe that the gain scores are more closely related to eighth-grade curriculum measures than the eighth-grade scores which reflect all prior school experiences. Ranked according to the eighth-grade achievement gain measure, the United States did worse than its rank by eighth-grade mean scores, scoring lower than all but four countries in mathematics and three in science.

3. Schmidt et al. (2001) speculate that the varying effects of standards may be related to differences in governance among nations. In the United States, decentralized governance makes it difficult to implement standards consistently across jurisdictions.

4. Additional work available from the U.S. TIMSS Research Center at Michigan State University does a similar comparison with science standards.

5. Valverde et al. (2002) note that in many nations this deficiency in textbooks may be compensated by strengths in other policy instruments such as teacher training practices or national examinations. They suggest that deficient textbooks are more harmful in countries like the United States that lack alternative methods of influencing the implementation of curriculum on a national level.

6. Their analysis is based on the type and number of different courses available in different schools, the percentage of students enrolled in those courses, textbooks used, and the amount of time teachers spent on different topics within those courses. Courses were categorized by researchers as remedial, regular, enriched, prealgebra, algebra I, and geometry, based on topics covered.

7. If courses are characterized by textbook rather than course title, then the percentage of U.S. eighth-grade students studying algebra $(14 \%)$ is even less than reported elsewhere.

8. Video clips from this report are available on CD-ROM from the National Center on Education Statistics or online at http:// nces.ed.gov/pubs2003/ timssvideo.

9. A number of these differences are highlighted here. For a more comprehensive description, see Hiebert et al. (2003). 
10. There is no evidence to suggest that this difference or any of the variations reported here account for differences in student achievement. For example, in the Czech Republic, which also scored higher than the United States, lessons devote even more time to review of content.

11. Other nations varied widely on this measure, but the difference is especially marked in the case of the United States.

12. Japanese lessons are of interest as they are distinct from those in other sampled nations and because Japanese students have demonstrated consistently high achievement on TIMSS tests. There is, however, no evidence to suggest that the differences reported here account for the high achievement of Japanese students. For example, lessons in Hong Kong, which ranked slightly higher than Japan on the TIMSS-1999 mathematics assessment, do not share these characteristics.

13. This figure represents the average across all lessons; no single lesson is likely to show a combination of all topics.

14. Research conducted at CRESP using cross-national multivariate prediction models for student achievement, for example, found three variables that together accounted for $84 \%$ of the total cross-national variability in mathematics achievement. These predictor variables, all inversely related to achievement, were: (1) the national percentage of students who strongly agreed that they usually do well in math, (2) the national percentage of students who strongly agreed that to do well in math they need good luck, and (3) the national percentage of students who strongly agreed that their mother thought it was important for them to be good at sports. In science, four national-level predictor variables accounted for $85 \%$ of the total variability among nations in science achievement. They were: (1) the school provides special science enrichment activities (positive relationship with achievement), (2) the fact that a school's capacity to provide instruction was affected "a lot" by a shortage or inadequacy of science laboratory equipment and materials (inverse relationship with achievement), (3) the hours students work on paid jobs per week (inverse relationship with achieve- ment), and (4) the national percentage of students who strongly agreed that to do well in science they need good luck (inverse relationship with achievement).

15. See Nelson (2002) for a summary of how some TIMSS benchmarking jurisdictions are approaching this challenge.

16. TIMSS student assessments were given at grades 3 and 4 (TIMSS fourthgrade assessment), 7 and 8 (TIMSS eighthgrade assessment), and 12 (TIMSS end-ofsecondary-school assessment). In addition, the TIMSS eighth-grade assessment was administered in grades 9-12 to yield data on achievement growth across grades in specific subtopics.

17. To learn more about this work, contact Cynthia Banach, Assistant Superintendent, St. Clair Intermediate School District at (810) 364-8990.

\section{References}

Akiba, M., LeTendre, G., Baker, D., \& Goesling, B. (2002). Student victimization: National and school system effects on school violence in 37 nations. American Journal of Education Research, 39(4), 829-853.

Baker, D. (2002). Should we be more like them? American high school achievement in cross-national comparison. Brookings papers on education policy. Washington, DC: The Brookings Institution.

Baker, D., Goesling, B., \& LeTendre, G. (2002). Socio-economic status, school quality, and national economic development: A crossnational analysis of the "Heyneman-Loxley Effect" on mathematics and science achievement. Comparative Education Review, 46(3), 291-312.

Boe, E., May, H., Shin, S., \& Boruch, R. (2002). Student task persistence in the Third International Mathematics and Science Study: A major source of achievement differences at the national, classroom, and student levels. Philadelphia: Center for Research and Evaluation in Social Policy, University of Pennsylvania.

Cogan, L., Schmidt, W., \& Wiley, D. (2001). Who takes what math and in which track? Using TIMSS to characterize U.S. students' eighth-grade mathematics learning opportunities. Educational Evaluation and Policy Analysis, 23(4), 323-341. 
Dunson, M. (2000). From research to practice and back again: TIMSS as a tool for educational improvement (CPRE Policy Brief No. RB-30). Philadelphia: Consortium for Policy Research in Education, University of Pennsylvania.

Hiebert, J., et al. (2003). Highlights from the TIMSS 1999 video study of eighth-grade mathematics teaching. Washington, DC: National Center on Education Statistics.

Nelson, D. (2002). Using TIMSS to inform policy and practice at the local level (CPRE Policy Brief No. RB-36). Philadelphia: Consortium for Policy Research in Education, University of Pennsylvania.

Schmidt, W., et al. (2001). Why schools matter: A cross-national comparison of curriculum and learning. San Francisco: Jossey-Bass.

Schmidt, W., McKnight, C., \& Raizen, S. (1997). A splintered vision: An investigation of U.S. science and mathematics education. Boston: Kluwer Academic Publishers.

Schmidt, W., Cogan, L., Houang, R., Markle, B., Middlestead, A., \& Wang, H. (2002). Mirroring the U.S.: Initial findings from the PRISM initiative. Ann Arbor, MI: U.S. TIMSS National Research Center, Michigan State University.

Schmidt, W., Houang, R., \& Cogan, L. (2002, Summer). A coherent curriculum: The case of mathematics. American Educator, 1-18.

Valverde, G., Bianchi, L., Wolfe, R., Schmidt, W., \& Houang, R. (2002). According to the book: Using TIMSS to investigate the translation of policy into practice through the world of textbooks. Norwell, MA: Kluwer Academic Publishers.

\section{Further Information on TIMSS}

\section{CPRE Policy Briefs}

Dunson, M. (2000). From research to practice and back again: TIMSS as a tool for educational improvement. (CPRE Policy Brief No. RB-30). Philadelphia: Consortium for Policy Research in Education, University of Pennsylvania. (Free-of-charge)

http://www.cpre.org/Publications/rb30.pdf

Nelson, D. (2002). Using TIMSS to inform policy and practice at the local level. (CPRE Policy Brief No. RB-36). Philadelphia: Consortium for Policy Research in Education, University of Pennsylvania. (Free-of-charge)

http://www.cpre.org/Publications/rb36.pdf

\section{TIMSS Research Centers}

The International Study Center, Lynch School of Education, Boston College

Telephone: (617) 552-1600

http://timss.bc.edu/index.html

\section{U.S. TIMSS National Research Center, Michigan State University, College of Edu- cation}

Telephone: (517) 353-7755

http://ustimss.msu.edu/ 


\section{Recent CPRE Publications}

The following is a list of selected publications reporting on research conducted by the Consortium for Policy Research in Education. Research reports are available for a nominal fee; policy briefs and technical reports are available free-of-charge. For further information, please see below, call (215) 573-0700, ext. 1, or visit us on the world wide web at www.cpre.org

\section{Research Reports:}

What Large-scale, Survey Research Tells Us About Teacher Effects on Student Achievement: Insights from the Prospects Study of Elementary Schools

Brian Rowan, Richard Correnti, and Robert Miller, November 2002, RR-051 (\$5.00)

This report examines conceptual and methodological issues that arise when educational researchers use data from large-scale, survey research studies to investigate teacher effects on student achievement.

\section{The Merck Institute for Science Education: A Successful Intermediary for Educational} Reform

Tom Corcoran, March 2003, RR-052 (\$5.00)

For nearly 10 years, CPRE has evaluated the Merck Institute for Science Education's (MISE) partnership with four school districts in New Jersey and Pennsylvania, providing MISE staff with feedback on the progress of their work and assessing MISE's impact on schools, teachers, and students. This summary report looks at the last 10 years of MISE and how a technical assistance organization works with school districts to change classroom practice.

Teacher Leadership as a Strategy for Instructional Improvement: The Case of the Merck Institute for Science Education

Kate Riordan, March 2003, RR-053 (\$5.00)

Developing teacher leaders in schools who are willing and able to serve as champions of instructional reforms and provide support to other teachers who are implementing them has been a major strategy used by MISE. This report examines MISE's approach to the development of teacher leadership and the effects that this strategy has had on its partner districts and schools.

Copies of these reports are available for $\$ 5.00$ each. Prices include book-rate postage and handling. Make checks payable to Trustees of the University of Pennsylvania. Sorry, we cannot accept returns, credit card orders, or purchase orders. Sales tax is not applicable. To obtain copies, write:

CPRE Publications

Graduate School of Education

University of Pennsylvania

3440 Market Street, Suite 560

Philadelphia, PA 19104-3325

Quantity discounts are available. For more information, please call (215) 573-0700. 


\section{Technical Reports:}

\section{Systemic Reform in Practice: Merck Institute for Science Education}

March 2003

This publication reviews how MISE and its partners addressed seven specific domains of district action in a systemic way and, thereby, altered the norms of classroom practice.

\section{Case Studies About the Work of the Merck Institute for Science Education: Franklin Elementary School, Rahway, NJ}

Siobhan McVay, March 2003 (No charge)

\section{Highland Avenue School, Linden, NJ}

Claire Passantino, March 2003 (No charge)

Inglewood Elementary School, Lansdale, PA

Siobhan McVay, March 2003 (No charge)

\section{Three Bridges and Holland Brook Elementary Schools, Readington Township, NJ}

Patricia J. Kannapel, March 2003 (No charge)

The Impact of Standards-based Reform in Duval County, Florida, 1999-2002

Jonathan Supovitz and Brooke Snyder Taylor, May 2003 (No charge)

Describes the efforts of the Duval County, Florida schools to improve the learning of all students by implementing standards-based reform in schools throughout the district with the intent to systematically improve teaching and learning.

\section{The Impact of America's Choice on Student Performance in Duval County, Florida} Jonathan Supovitz, Brooke Snyder Taylor, and Henry May, November 2002 (No charge)

Reports on the impact of the America's Choice School Design on student standardized test performance in Duval County, Florida.

The Relationship Between Teacher Implementation of America's Choice and Student Learning in Plainfield, New Jersey

Jonathan Supovitz and Henry May, February 2003 (No charge)

Explores the relationship between teachers' implementation of different aspects of America's Choice and the learning gains of their students.

The Heart of the Matter: The Coaching Model in America's Choice Schools

Susan Poglinco, Amy Bach, Kate Hovde, Sheila Rosenblum, Marisa Saunders, and Jonathan Supovitz, May 2003 (No charge)

Explores the coaching model in first-year America's Choice schools in grades K-8 as it relates to the implementation of readers and writers workshops.

Copies of the above publications are available free-of-charge. To obtain copies, please email us at cpre@gse.upenn.edu, or call us at (215) 573-0700. 


\section{Nondiscrimination Statement}

The University of Pennsylvania values diversity and seeks talented students, faculty, and staff from diverse backgrounds. The University of Pennsylvania does not discriminate on the basis of race, sex, sexual orientation, religion, color, national or ethnic origin, age, disability, or status as a Vietnam era veteran or disabled veteran in the administration of educational policies, programs, or activities; admissions policies, scholarships, or loan awards; and athletic or University-administered programs or employment. Questions or complaints regarding this policy should be directed to Executive Director, Office of Affirmative Action, 1133 Blockley Hall, Philadelphia, PA 191046021 or 215-898-6993 (Voice) or 215-898-7803 (TDD).

\section{GRE Brifery}

Graduate School of Education

University of Pennsylvania

3440 Market Street, Suite 560

Philadelphia, PA 19104-3325

\section{About CPRE}

The Consortium for Policy Research in Education (CPRE) studies alternative approaches to education reform in order to determine how state and local policies can promote student learning. Currently, CPRE's work is focusing on accountability policies, efforts to build capacity at various levels within the education system, methods of allocating resources and compensating teachers, governance changes like charters and mayoral takeovers, finance, student and teacher standards, and student incentives. The results of this research are shared with policymakers, educators, and other interested individuals and organizations in order to promote improvements in policy design and implementation.

CPRE unites five of the nation's leading research institutions to improve elementary and secondary education through research on policy, finance, school reform, and school governance. Members of CPRE are the University of Pennsylvania, Harvard University, Stanford University, the University of Michigan, and the University of Wisconsin-Madison.

CPRE Policy Briefs are published by CPRE. To learn more about CPRE research or publications, please call 215-573-0700 or access CPRE publications at www.cpre.org; www.wcer.wisc.edu/cpre/; or www.sii.soe.umich.edu. 